Article

\title{
Efficient Removal of Bisphenol A Using Nitrogen-Doped Graphene-Like Plates from Green Petroleum Coke
}

\author{
Zhipeng Liu ${ }^{1}$, Quanyong Wang ${ }^{2}$, Bei Zhang ${ }^{1}$, Tao $\mathrm{Wu}^{3, *}$ and Yujiang $\mathrm{Li}^{1, *}$ \\ 1 Shandong Provincial Research Center for Water Pollution Control, School of Environmental Science \\ and Engineering, Shandong University, Jinan 250100, China; 201812787@mail.sdu.edu.cn (Z.L.); \\ zhangbeisdu@163.com (B.Z.) \\ 2 China Urban Construction Design and Research Institute Co., Ltd., Jinan 250101, China; \\ hkyyswang@163.com \\ 3 Key Laboratory of Colloid and Interface Science of Education Ministry, Shandong University, \\ Jinan 250100, China \\ * Correspondence: wutao@sdu.edu.cn (T.W.); yujiang@sdu.edu.cn (Y.L.); \\ Tel.: +86-158-5319-6759 (T.W.); +86-159-5317-9619 (Y.L.)
}

Academic Editors: Filippo Parisi and Matej Baláž

Received: 9 June 2020; Accepted: 30 July 2020; Published: 3 August 2020

\begin{abstract}
Green petroleum coke, a form of industrial waste produced in the oil-refining process, was used to synthesize nitrogen-doped graphene-like plates (N-GLPs) together with melamine. In this study, characterization and batch experiments were performed to elucidate the interaction mechanism of N-GLPs and bisphenol A (BPA). Structural analysis of N-GLPs, including scanning electron microscopy (SEM), X-ray diffraction (XRD), Fourier transform infrared spectroscopy (FT-IR), Brunauer-Emmett-Teller (BET), and X-ray photoelectron spectroscopy (XPS), showed an obvious graphene-like structure and successful nitrogen doping. In addition, compared with $8.0 \mathrm{~m}^{2} / \mathrm{g}$ for green petroleum coke, the BET surface area of N-GLPs markedly increased to $96.6 \mathrm{~m}^{2} / \mathrm{g}$. The influences of various factors, including contact time, temperature, and initial $\mathrm{pH}$ on BPA removal efficiency were investigated. It was found that $92.0 \%$ of BPA was successfully removed by N-GLPs at $50{ }^{\circ} \mathrm{C}$. Based on the adsorption experiments, it was shown that electrostatic attraction, hydrogen bonding, and $\pi-\pi$ interaction enhanced the adsorption capacity of N-GLPs for BPA. According to the thermodynamic data, the adsorption process was spontaneous, physical, and endothermic in nature. Therefore, $\mathrm{N}$-GLPs are efficient adsorbent material to remove BPA from wastewater.
\end{abstract}

Keywords: green petroleum coke; nitrogen doping; bisphenol A; electrostatic attraction; adsorption

\section{Introduction}

As a phenolic compound with high production, bisphenol A (BPA) is widely utilized in the manufacturing of epoxy resins and polycarbonate plastics [1,2]. Due to its pervasive application, a tremendous amount of BPA is discharged into the environment. Indeed, BPA has been confirmed to be present in a broad variety of areas, such as water systems, air, sediment, landfills, and some food matrices [3]. BPA is known as an endocrine-disrupting compound and may lead to deleterious effects on humans due to its estrogenic activity [4]. As the existence of BPA in water environments constitutes a potential major hazard for both humans and aquatic organisms, it is critical to develop an efficient method to remove BPA.

Among the various methods available for the removal of BPA, adsorption has attracted great attention due to its economic applicability, high efficiency, easy operation, and hypotoxicity $[5,6]$. The particular adsorbent used in an adsorption process determines both adsorption efficiency and cost 
and thus plays a key role in its use and effectiveness. Carbonaceous materials, including activated carbon, graphene, graphene oxide, and reduced graphene oxide, have been widely utilized in water purification processes. They can achieve rapid adsorption rates due to their large surface area and pore volume [7]. However, these adsorbents possess numerous disadvantages, such as high production cost, low productivity, and challenging regeneration. All of these disadvantages have demonstrated the necessity to identify or develop a novel adsorbent with superior adsorption efficiency and lower production cost to remove BPA from wastewater.

Green petroleum coke is a by-product from the carbonization of petroleum feedstock and oil-refining process [8,9]. It offers numerous advantages, such as high fixed carbon content, low content of ash, extensive sources, low cost, and abundant benzene rings or aromatic domains [10,11]. However, as a by-product with high production, a vast amount of green petroleum coke is not utilized in a timely manner and is instead stacked. This presents a major environmental concern because soluble substances in green petroleum coke will permeate into the groundwater and soil during the leaching process [12]. Consequently, the development of a method to promptly and effectively utilize green petroleum coke is needed. Considering its major advantages, it is feasible for green petroleum coke to serve as a raw adsorbent material to deal with BPA in aqueous solution.

In this work, we report a cost-effective method for synthesizing nitrogen-doped graphene-like plates from green petroleum coke as a novel adsorption material. Green petroleum coke was calcined at high temperature as a post-treatment to obtain petroleum coke as a precursor. Melamine was chosen as the nitrogen source for the nitrogen-doped graphene-like plates (N-GLPs). Nitrogen doping on a carbon network has been confirmed to introduce positive charge and then augment electrostatic interaction [13]. In addition, nitrogen doping on petroleum coke would obtain pyridinic $\mathrm{N}$, pyrrolic $\mathrm{N}$, and graphitic $\mathrm{N}$, thus regularizing the crystal structure [14]. Moreover, a $\pi-\pi$ interaction might form between nitrogen-doped graphene-like plates and benzene rings in BPA. Scanning electron microscopy (SEM), energy-dispersive X-ray spectroscopy (EDX), X-ray diffraction (XRD), Fourier transform infrared spectroscopy (FT-IR), the Brunauer-Emmett-Teller (BET) specific surface area, and X-ray photoelectron spectroscopy (XPS) were utilized to analyze the physicochemical properties of nitrogen-doped graphene-like plates. Subsequently, the influence of adsorption conditions, including contact time, temperature, and $\mathrm{pH}$, were investigated, thereby determining the optimum conditions for maximum removal efficiency of BPA. The adsorption mechanism of BPA was also elucidated with the structure of nitrogen-doped graphene-like plates and the adsorption isotherms.

\section{Results and Discussions}

\subsection{Optimization of Adsorption Materials}

\subsubsection{Effect of N-Doped Temperature}

$\mathrm{N}$-doped temperature is a key factor affecting a material's physicochemical properties. For the variation in physicochemical properties, we used several techniques, e.g., SEM, XED, FT-IR, BET, and XPS, to characterize the obtained materials. In this work, we fixed the $\mathrm{N}$-doping time at $2 \mathrm{~h}$ and varied the $\mathrm{N}$-doped temperature to 350,550 , and $750{ }^{\circ} \mathrm{C}$ to produce three $\mathrm{N}$-doped samples. After calcination and nitrogen doping, green petroleum coke particles transformed into N-GLPs. We defined the three obtained N-doped samples as N-GLPs $350_{2}$, N-GLPs $550_{2}$, and N-GLPs $750_{2}$.

\section{SEM}

SEM was performed to analyze the morphologies and microstructures of the green petroleum coke and N-GLP samples obtained from calcination at 350, 550, and $750{ }^{\circ} \mathrm{C}$. SEM images of green petroleum coke, N-GLPs $350_{2}$, N-GLPs $550_{2}$, and N-GLPs $750_{2}$ composites at the same magnification are shown in Figure 1. Compared with green petroleum coke's irregular granular structure (Figure 1a), N-GLP samples with N-doping and thermal processing (Figure 1b-d) showed a more regular and 
larger lamella structure. The SEM images indicated that calcination and nitrogen doping transformed the green petroleum coke into a more regular and neater lamella structure. Moreover, the SEM image of N-GLPs $750_{2}$ (Figure $1 \mathrm{~d}$ ) demonstrated that N-doping at $750{ }^{\circ} \mathrm{C}$ obtained the N-GLP sample with the smoothest lamellar structure among the samples mentioned above.
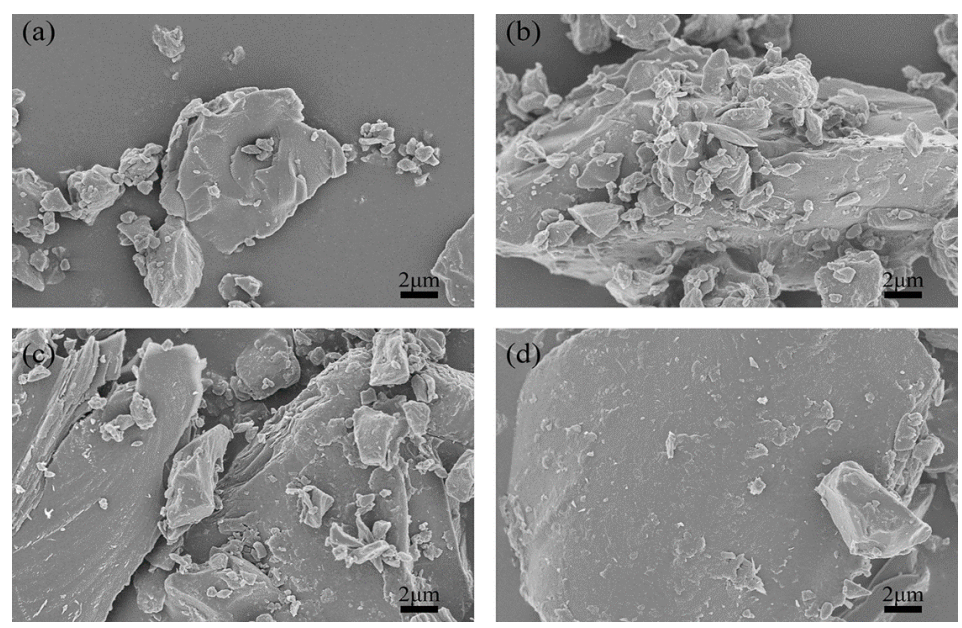

Figure 1. Effect of $\mathrm{N}$-doped temperature on material's optimization: (a) green petroleum coke, (b) nitrogen-doped graphene-like plates (N-GLPs) $350_{2}$, (c) N-GLPs $550_{2}$, and (d) N-GLPs $750_{2}$.

XRD

X-ray diffraction analysis determined the crystal structure in green petroleum coke and N-GLP samples by measuring the reflection angle from the crystal lattice. The XRD profiles of green petroleum coke, graphene, N-GLPs $350_{2}$, N-GLPs $550_{2}$, and N-GLPs $750_{2}$ are given in Figure 2. As shown in Figure 2, green petroleum coke, graphene, and all of the N-GLP samples exhibited a characteristic peak at $2 \theta=26^{\circ}$ on their XRD diffraction spectrum. With the temperature increasing, a small peak at $2 \theta=44^{\circ}$ on XRD diffraction spectrums of N-GLP samples could be identified. The peak at $2 \theta=26^{\circ}$ and $2 \theta=44^{\circ}$ corresponded to crystalline regions of diffraction from layering of graphitic carbons and formation of small 2D lattices, respectively [15]. In addition, the peak height and intensity at $2 \theta=26^{\circ}$ of the N-GLP samples were higher than those of green petroleum coke, which demonstrated that green petroleum coke was led to an orderly crystal structure through calcination and N-doping. Compared with other samples, N-GLPs $750_{2}$ (Figure 2e) exhibited the highest peak intensity. The XRD results revealed that the green petroleum coke tended to be graphitized to a greater extent with N-doping and the increase in temperature [16].

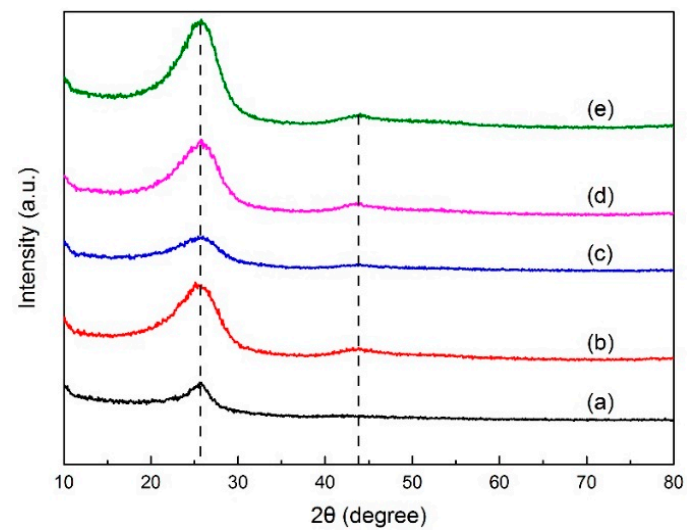

Figure 2. X-ray diffraction (XRD) patterns of (a) green petroleum coke, (b) graphene, (c) N-GLPs $350_{2}$, (d) N-GLPs $550_{2}$, and (e) N-GLPs $750_{2}$. 
FT-IR

Information about surface functional groups and chemical bonding behavior was obtained by FT-IR $[17,18]$. The FT-IR spectra of green petroleum coke, N-GLPs $350_{2}$, N-GLPs $550_{2}$, and N-GLPs $750_{2}$ are shown in Figure 3. For green petroleum coke (Figure 3a), the bands in the FT-IR spectrum can be summarized as follows: (1) the typical band at $3446 \mathrm{~cm}^{-1}$ can be attributed to -OH stretching vibration; (2) the bands at 3044 and $2915 \mathrm{~cm}^{-1}$ can be assigned to $\mathrm{C}-\mathrm{H}$ asymmetric and symmetric stretching vibrations of $\mathrm{CH}_{2}$ and $\mathrm{CH}_{3}$ groups [19]; (3) the bands at 1596 and $1438 \mathrm{~cm}^{-1}$ can be identified as C-C stretching vibration; and (4) the bands at 869,806 , and $747 \mathrm{~cm}^{-1}$ can be ascribed to the characteristic peaks of aromatic structure [20,21]. The characteristic bands of green petroleum coke decreased apparently with increasing N-doping temperature. In addition, the bands at 3044 and $2915 \mathrm{~cm}^{-1}$ disappeared, indicating that calcination removed some aromatic hydrocarbons with small molecular weight from the green petroleum coke. Compared with green petroleum coke, the FT-IR spectrum of N-GLPs exhibited a typical transformation process of bands with increasing N-doping temperature. For the FT-IR spectrum of N-GLPs $750_{2}$ (Figure 3d), five main regions were identified: (1) the bands at 3864 and $3743 \mathrm{~cm}^{-1}$ can be assigned to $-\mathrm{OH}$ stretching vibration [22]; (2) the band at $3447 \mathrm{~cm}^{-1} \mathrm{can}^{-}$ be attributed to N-H symmetric stretching vibration [23]; (3) the band at $1636 \mathrm{~cm}^{-1}$ can be identified as N-H in-plane deformation vibration [23-25]; (4) the band at $1520 \mathrm{~cm}^{-1}$ can be ascribed to $\mathrm{C}=\mathrm{N}$ stretching vibration, while the band at $1052 \mathrm{~cm}^{-1}$ can be assigned to C-N stretching vibration [25,26]; and (5) the bands at 753 and $630 \mathrm{~cm}^{-1}$ can be attributed to $-\mathrm{NH}_{2}$ vibration bands [27]. All of these characteristics indicated the existence of $\mathrm{N}$-containing functional groups and the successful doping of nitrogen in N-GLP samples.

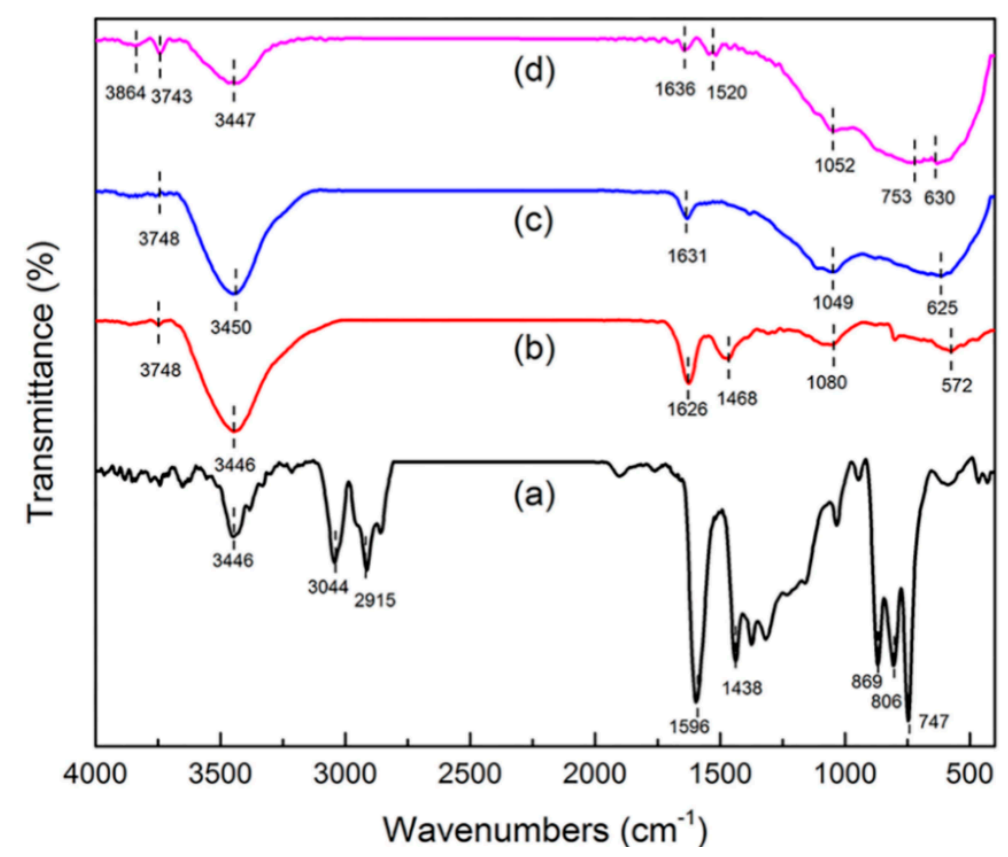

Figure 3. Fourier transform infrared spectroscopy (FT-IR) spectra of (a) green petroleum coke, (b) N-GLPs $350_{2}$, (c) N-GLPs $550_{2}$, and (d) N-GLPs $750_{2}$.

BET

It is important to measure specific surface area and pore volume of green petroleum coke and N-GLP samples in order to determine their physicochemical properties [28]. To identify the pore volume and specific surface area, we performed $\mathrm{N}_{2}$ sorption measurements. The BET method from the $\mathrm{N}_{2}$ adsorption isotherm was carried out to determine the BET surface area $\left(\mathrm{S}_{\mathrm{BET}}\right)$ of green petroleum coke and N-GLP samples, while the pore volume was obtained by holding the $\mathrm{N}_{2}$ volume at a relative pressure of $\mathrm{P} / \mathrm{P}_{0}=0.998$. The $\mathrm{S}_{\mathrm{BET}}$ and pore volume $\left(\mathrm{V}_{\mathrm{p}}\right)$ of the green petroleum coke and $\mathrm{N}$-doped 
samples are listed in Table 1. The green petroleum coke only possessed a small $\mathrm{S}_{\mathrm{BET}}$ and $\mathrm{V}_{\mathrm{p}}$ of $8.0 \mathrm{~m}^{2} / \mathrm{g}$ and $0.013 \mathrm{~cm}^{3} / \mathrm{g}$, respectively. After thermal processing and N-doping, the $S_{\mathrm{BET}}$ of N-GLPs $350_{2}$, N-GLPs $550_{2}$, and N-GLPs $750_{2}$ increased to $35.9,44.8$, and $65.4 \mathrm{~m}^{2} / \mathrm{g}$, respectively. In addition, the $\mathrm{V}_{\mathrm{p}}$ of N-GLPs $350_{2}$, N-GLPs $550_{2}$, and N-GLPs $750_{2}$ also increased to $0.029,0.040$, and $0.055 \mathrm{~cm}^{3} / \mathrm{g}$, respectively. These analysis data indicated that N-GLP samples with a larger specific surface area and higher porosity would constitute potential adsorbents for BPA.

Table 1. Surface area and porous volume of the green petroleum coke and N-doped samples.

\begin{tabular}{ccc}
\hline Sample & $\mathbf{S}_{\text {BET }}\left(\mathbf{m}^{2} / \mathbf{g}\right)$ & $\mathbf{V}_{\mathbf{p}}\left(\mathbf{c m}^{\mathbf{3}} / \mathbf{g}\right)$ \\
\hline Green petroleum coke & 8.0 & 0.013 \\
N-GLPs $350_{2}$ & 35.9 & 0.029 \\
N-GLPs $550_{2}$ & 44.8 & 0.040 \\
N-GLPs $750_{2}$ & 65.4 & 0.055 \\
\hline
\end{tabular}

XPS

The elemental composition and nitrogen bonding configurations in green petroleum coke and N-GLP samples were obtained by XPS characterizations. The detailed characteristics of the nitrogen species on the surface of the samples were probed by high-resolution $\mathrm{N}$ 1s spectra, as shown in Figure 4. For all samples, the raw peaks of $\mathrm{N} 1 \mathrm{~s}$ were deconvoluted into three types of nitrogen species. The peaks around 398.8, 399.8, and $401.3 \mathrm{eV}$ were ascribed to pyridinic $\mathrm{N}$, pyrrolic $\mathrm{N}$, and graphitic $\mathrm{N}$, respectively [29-31]. The ratio of pyrrolic N:pyridinic N:graphitic $\mathrm{N}$ was 1:0.20:0.36 (overall 3.97 at \%), 1:6.22:1.98 (overall 5.59 at\%), and 1:2.20:1.68 (overall 6.21 at \%) for N-GLPs $350_{2}$, $\mathrm{N}-\mathrm{GLPs} 550_{2}$, and N-GLPs $750_{2}$, respectively. With increasing thermal annealing temperature, more graphitic $\mathrm{N}$ incorporated into the graphene-like plane due to superior thermal stability compared to pyrrole-like $\mathrm{N}$ [32-35]. Moreover, the binding energy of graphitic $\mathrm{N}$ increased with the increase in temperature, which was due to successful nitrogen doping [36-38]. The increase in graphitic $\mathrm{N}$ content indicate that N-GLPs can be successfully synthesized by calcining green petroleum coke with melamine. Moreover, nitrogen species and doping content can be controlled by synthesis conditions. Higher temperatures cause more nitrogen atoms to be doped into N-GLPs films, and graphitic N structures are formed preferably at higher temperatures [39]. Combining the nitrogen compositional species and nitrogen content, N-GLPs $750_{2}$ at $750{ }^{\circ} \mathrm{C}$ (Figure $4 \mathrm{~d}$ ) obtained the ideal N-doping effect.

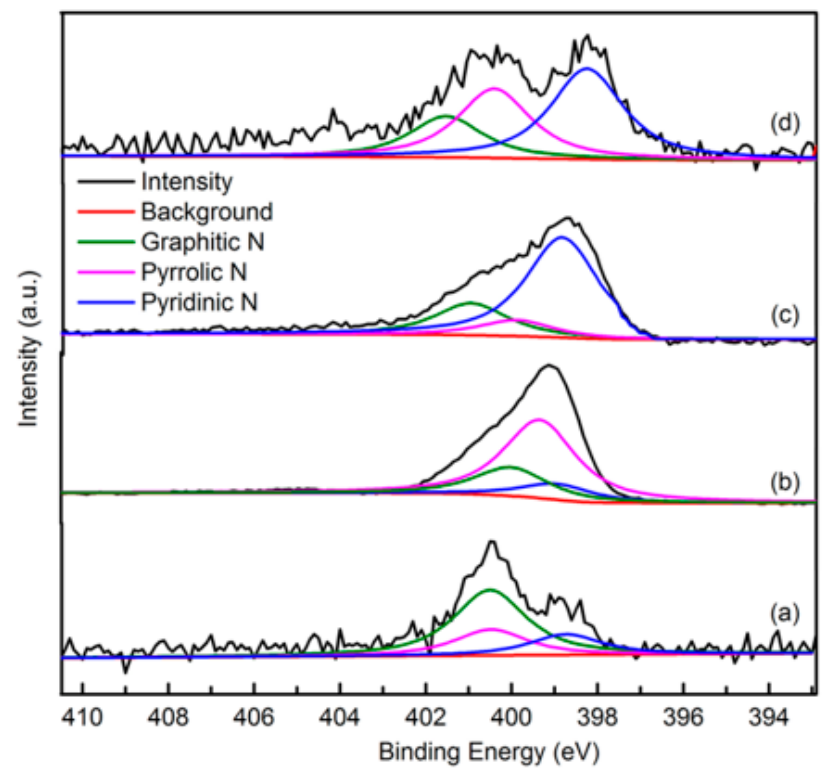

Figure 4. Narrow scanning N 1s X-ray photoelectron spectroscopy (XPS) spectra of (a) green petroleum coke, (b) N-GLPs $350_{2}$, (c) N-GLPs $550_{2}$, and (d) N-GLPs $750_{2}$. 
Based on the analysis results of all characterizations, we chose $750{ }^{\circ} \mathrm{C}$ as the most appropriate $\mathrm{N}$-doped temperature.

\subsubsection{Effect of N-Doping Time}

$\mathrm{N}$-doping time is another crucial factor affecting a material's physicochemical properties, thereby further influencing a material's adsorption capacities. In this study, we fixed $\mathrm{N}$-doped temperature at $750{ }^{\circ} \mathrm{C}$ and varied the $\mathrm{N}$-doping time from 2 to $6 \mathrm{~h}$ to produce three $\mathrm{N}$-doped samples. The obtained three N-doping samples were defined as N-GLPs $750_{2}, \mathrm{~N}-\mathrm{GLPs} 750_{4}$, and N-GLPs $750_{6}$, corresponding to an $\mathrm{N}$-doping time of 2,4 , and $6 \mathrm{~h}$, respectively.

\section{SEM}

The morphological and structural features of green petroleum coke and N-GLP samples were characterized by SEM. SEM images of green petroleum coke, N-GLPs $750_{2}, \mathrm{~N}-\mathrm{GLPs} 750_{4}$, and N-GLPs $750_{6}$ composites are shown in Figure 5. All N-GLP samples obtained at $750{ }^{\circ} \mathrm{C}$ (Figure 5b-d) exhibited a regular lamella structure in contrast to that of green petroleum coke (Figure 5a). Furthermore, the lamella structure became more apparent with the increase in N-doping time. As shown in Figure $5 \mathrm{~d}$, the lamella of N-GLPs $750_{6}$ was extremely obvious and defined, demonstrating that the structure of $\mathrm{N}$-GLPs would become clear and ordered with longer N-doping time. Consequently, we identified that controlling the N-doping time at $6 \mathrm{~h}$ could obtain the N-GLP sample with the optimal lamella structure.
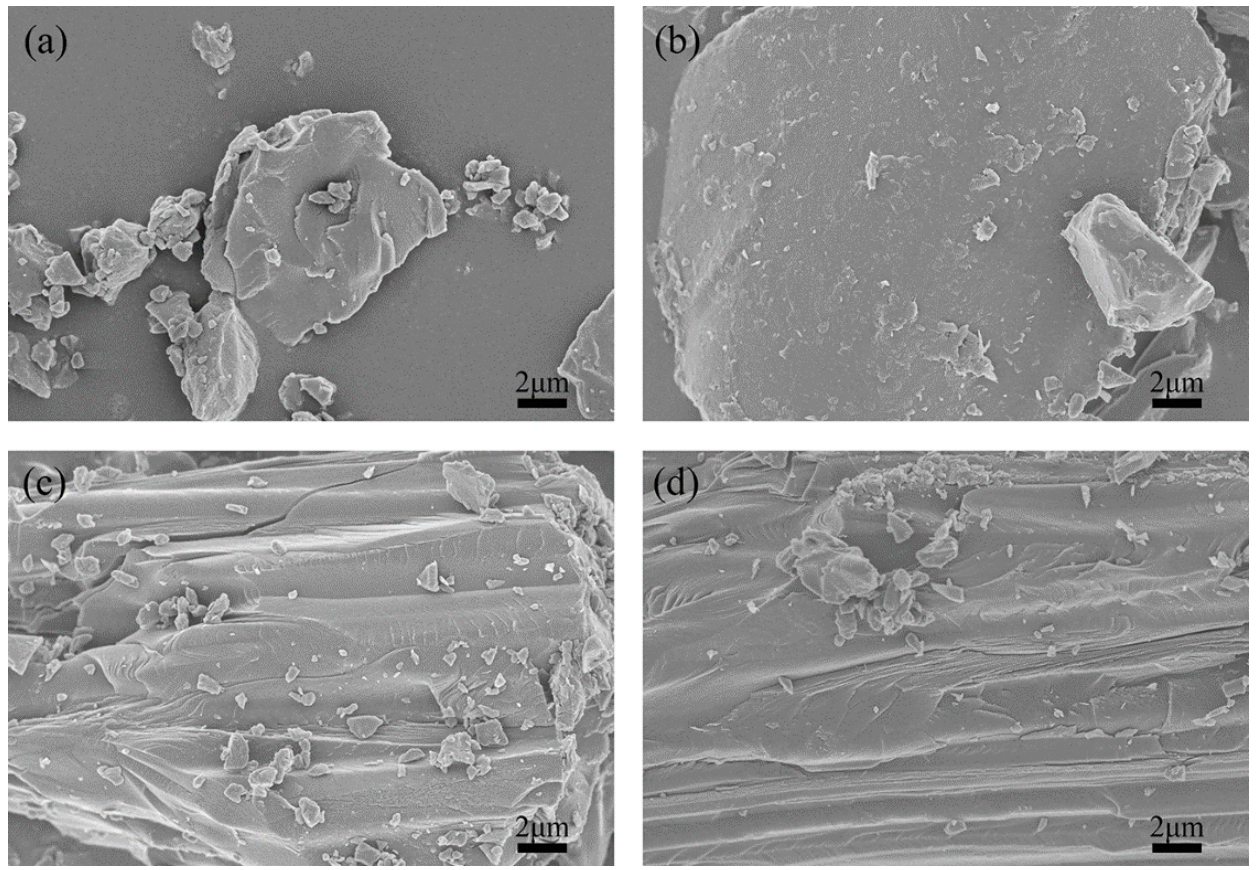

Figure 5. Effect of N-doping time on material's optimization: (a) green petroleum coke, (b) N-GLPs $750_{2}$, (c) N-GLPs $750_{4}$, and (d) N-GLPs $750_{6}$.

$\mathrm{XRD}$

The X-ray diffraction profiles of green petroleum coke, N-GLPs $750_{2}, \mathrm{~N}-\mathrm{GLPs} 750_{4}$, and N-GLPs $750_{6}$ are given in Figure 6 . All the XRD diffraction spectrum of N-GLP samples showed two characteristic peaks at $2 \theta=26^{\circ}$ and $2 \theta=44^{\circ}$, indicating that the crystal structures of N-GLP samples were identical to that of graphene. In addition, all of the N-GLP samples at $750{ }^{\circ} \mathrm{C}$ exhibited great peak height and intensity with narrow difference (Figure $6 \mathrm{~b}-\mathrm{d}$ ). Compared with other N-GLP samples, N-GLPs $750_{6}$ (Figure 6d) revealed a slightly higher peak intensity. In this case, we concluded that N-GLP samples 
obtained at $750{ }^{\circ} \mathrm{C}$ contained an excellent crystal structure and increasing the $\mathrm{N}$-doping time would narrowly improve the material property.

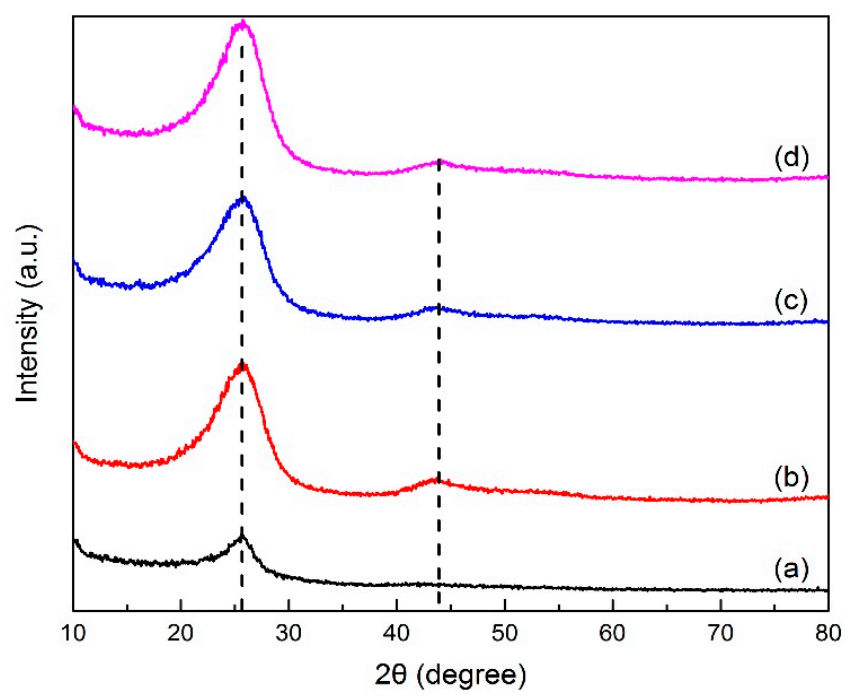

Figure 6. XRD patterns of (a) green petroleum coke, (b) N-GLPs $750_{2}$, (c) N-GLPs $750_{4}$, and (d) N-GLPs $750_{6}$.

\section{FT-IR}

The FT-IR spectra of green petroleum coke, N-GLPs $750_{2}, \mathrm{~N}$-GLPs $750_{4}$, and N-GLPs $750_{6}$ are shown in Figure 7. The N-GLP samples at $750{ }^{\circ} \mathrm{C}$ with different $\mathrm{N}$-doping times exhibited similar characteristic bands, while the N-GLPs $750_{4}$ and N-GLPs $750_{6}$ (Figure 7c,d) showed some differences. Compared with N-GLPs $750_{2}$ (Figure 7b), for the FT-IR spectrum of N-GLPs $750_{4}$ (Figure 7c), two main differences could be identified: (1) the broad band at 753 and $630 \mathrm{~cm}^{-1}$ of N-GLPs $750_{2}$ shifted to 700 and $632 \mathrm{~cm}^{-1}$ with increasing $\mathrm{N}$-doping time, and the intensity of these two bands was also lower, which indicated the decrease in - $\mathrm{NH}_{2}$ bands; and (2) the intensity of the band at $3447 \mathrm{~cm}^{-1}$ was higher, suggesting the improvement of $\mathrm{N}-\mathrm{H}$ concentration. The FT-IR spectra also revealed that the increase in $\mathrm{N}$-doping time would decrease unstable $-\mathrm{NH}_{2}$ bands and increase the concentration of stable N-H bands.

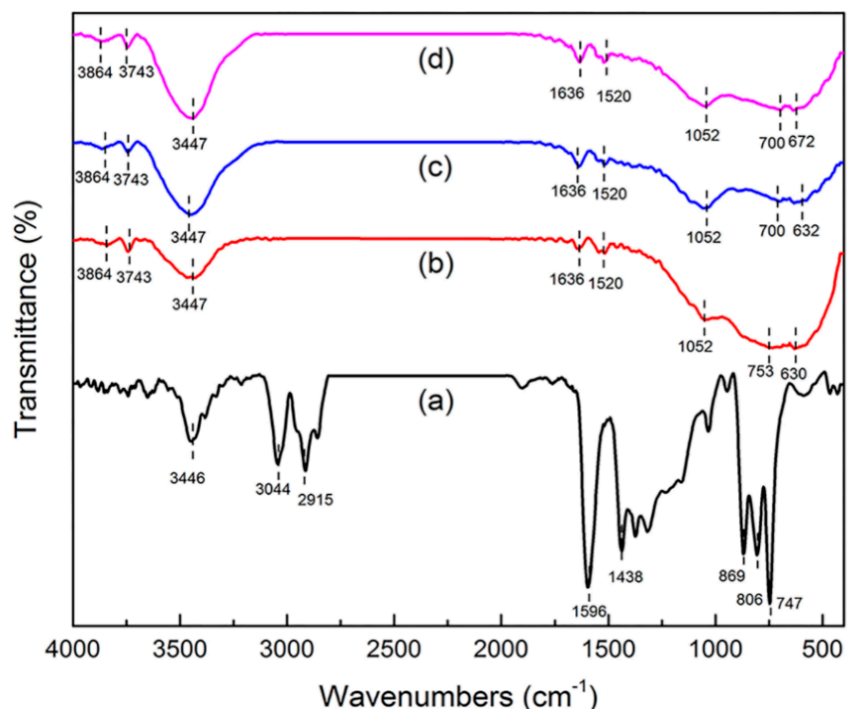

Figure 7. FT-IR spectra of (a) green petroleum coke, (b) N-GLPs 7502, (c) N-GLPs $750_{4}$, and (d) N-GLPs $750_{6}$. 
BET

The $\mathrm{S}_{\mathrm{BET}}$ and $\mathrm{V}_{\mathrm{p}}$ of the green petroleum coke and $\mathrm{N}$-doped samples of different $\mathrm{N}$-doping times are listed in Table 2. After extending the N-doping time, the $\mathrm{S}_{\mathrm{BET}}$ of N-GLPs $750_{2}, \mathrm{~N}-\mathrm{GLPs} 750_{4}$, and N-GLPs $750_{6}$ increased to $65.4,76.9$, and $96.6 \mathrm{~m}^{2} / \mathrm{g}$, respectively. The $\mathrm{V}_{\mathrm{p}}$ of N-GLPs $750_{2}, \mathrm{~N}-\mathrm{GLPs}$ $750_{4}$, and N-GLPs $750_{6}$ also rose to $0.055,0.068$, and $0.082 \mathrm{~cm}^{3} / \mathrm{g}$, respectively. Compared with green petroleum coke's low $S_{\text {BET }}$ and $V_{p}$ parameters, N-GLPs $750_{6}$ calcined at $750{ }^{\circ} \mathrm{C}$ for $6 \mathrm{~h}$ could obtain larger $\mathrm{S}_{\mathrm{BET}}$ and $\mathrm{V}_{\mathrm{p}}$ and thus offer great adsorption efficiency.

Table 2. Surface area and porous volume of the green petroleum coke and N-doped samples.

\begin{tabular}{|c|c|c|}
\hline Sample & $\mathrm{S}_{\mathrm{BET}}\left(\mathrm{m}^{2} / \mathrm{g}\right)$ & $V_{p}\left(\mathrm{~cm}^{3} / g\right)$ \\
\hline Green petroleum coke & 8.0 & 0.013 \\
\hline N-GLPs $750_{2}$ & 65.4 & 0.055 \\
\hline N-GLPs $750_{4}$ & 76.9 & 0.068 \\
\hline N-GLPs $750_{6}$ & 96.6 & 0.082 \\
\hline
\end{tabular}

XPS

The N 1s XPS spectrum of green petroleum coke and N-GLP samples at different N-doping times is illustrated in Figure 8. The ratio of pyrrolic N:pyridinic N:graphitic N was 1:2.20:1.68 (overall 6.21 at\%), 1:3.51:3.79 (overall 6.37 at\%), and 1:2.40:2.81 (overall 7.11 at \%) for N-GLPs 750, N-GLPs 750 N-GLPs $750_{6}$, respectively. With increasing N-doping time, the total content of doped nitrogen for N-GLP samples rose. In addition, the increase in graphitic N indicated that N-GLP samples at longer N-doping time would become more stable. N-GLPs $750_{6}$ (Figure $8 \mathrm{~d}$ ) contained the greatest nitrogen content and a stable nitrogen composition, thereby having the potential to improve the adsorption capacity.

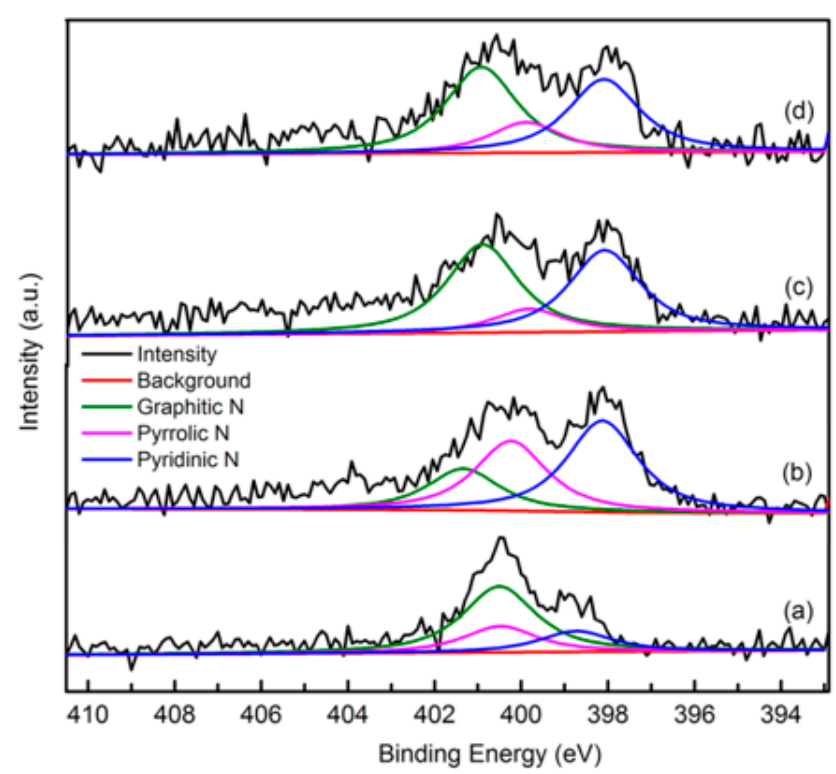

Figure 8. Narrow scanning N 1s XPS spectra of (a) green petroleum coke, (b) N-GLPs $750_{2}$, (c) N-GLPs $750_{4}$, and (d) N-GLPs $750_{6}$.

Combining the analysis results of all characterizations, we chose $6 \mathrm{~h}$ as the optimal N-doping time. Therefore, N-GLPs $750_{6}$ at $750{ }^{\circ} \mathrm{C}$ for $6 \mathrm{~h}$ was the ideal adsorbent used in further adsorption experiments. 


\subsection{Adsorption of BPA on N-GLPs $750_{6}$}

\subsubsection{Effect of Contact Time and Initial BPA Concentration}

The effect of contact time on the adsorption of BPA at various BPA concentrations was investigated at $30^{\circ} \mathrm{C}$. As shown in Figure 9, the adsorption capacity of N-GLPs $750_{6}$ rose with increasing initial BPA concentration. Moreover, with increasing contact time, it was observed that the adsorption capacity of N-GLPs $750_{6}$ rose rapidly in the first $10 \mathrm{~h}$ and then slowly attained the maximum adsorption capacity after $48 \mathrm{~h}$, indicating the adsorption equilibrium. Due to the large molecular size of BPA, it took a long time for BPA molecules to move to the surface of N-GLPs $750_{6}$ through Brownian movement. BPA then entered the adsorbent and was adsorbed under various forces, thus enhancing the adsorption time [40,41]. In further adsorption studies, based on the above results, $48 \mathrm{~h}$ was selected as the most appropriate contact time to reach the adsorption equilibrium. Pseudo-first-order and pseudo-second-order kinetic models were adopted to understand the adsorption behavior of N-GLPs $750_{6}$ for BPA [42-44]. As shown in Table S1 (Supplementary Materials), the adsorption kinetics of BPA on N-GLPs $750_{6}$ could be better fitted by the pseudo-second-order model (0.9993-1) than the pseudo-first-order model (0.8343-0.9152), indicating that the adsorption process was controlled by multiple factors. When the adsorption was far from equilibrium, the adsorption process was governed by the rate of surface reactions (electrostatic interaction and $\pi-\pi$ interaction), and the intraparticle diffusion became predominant before approaching equilibrium $[45,46]$.

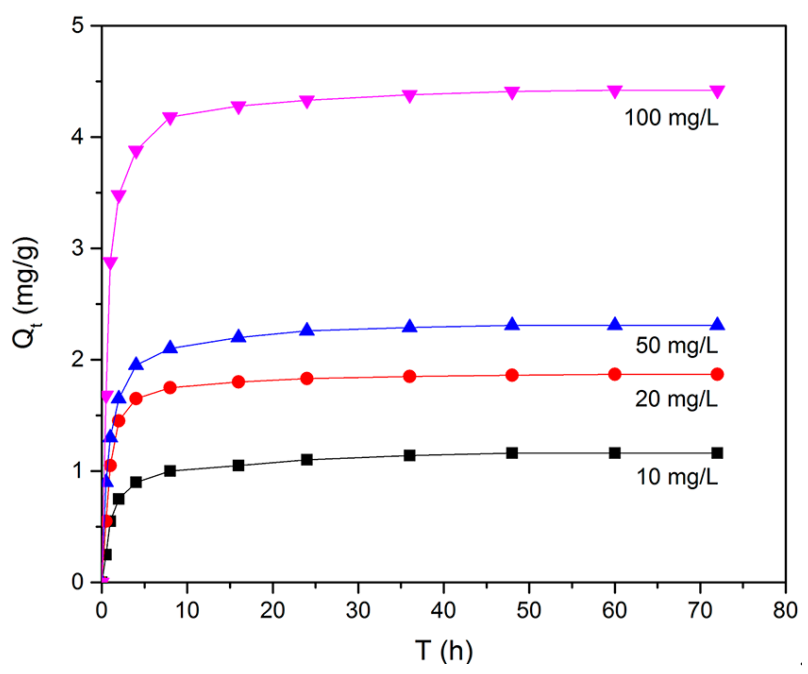

Figure 9. Effect of initial concentration and contact time on removal efficiency (experimental conditions: adsorbent dose $=7.0 \mathrm{~g} / \mathrm{L}$, initial concentration $=10-100 \mathrm{mg} / \mathrm{L}, \mathrm{pH}=6, \mathrm{~T}=30^{\circ} \mathrm{C}$ ).

\subsubsection{Effect of $\mathrm{pH}$}

As one of the most important adsorption parameters for practical water environmental remediation, the initial $\mathrm{pH}$ of a solution intensively influences the surface physicochemical properties of adsorbents [46]. As shown in Figure 10, the initial pH of the BPA aqueous solution was varied from 4 to 11 to investigate its effect on BPA removal efficiency. With the initial $\mathrm{pH}$ increasing to 8 , the removal efficiency of BPA on N-GLPs $750_{6}$ decreased slightly. Then, the removal efficiency decreased rapidly as the $\mathrm{pH}$ further increased. This phenomenon can be attributed to the following: (1) The charge of the adsorbent and pollutant. To determine the conditions of charge on N-GLPs $750_{6}$ layers and BPA aqueous solution, zeta potential was measured. The zeta potential values of N-GLPs $750_{6}$ dispersion and BPA solution were measured at $25^{\circ} \mathrm{C}$ in $10^{-3} \mathrm{~mol} / \mathrm{L} \mathrm{NaCl}$ solution, and the results are presented in Figure 11. A charge inversion from positive to negative was observed in the N-GLPs $750_{6}$ dispersion with the BPA solution containing a negative charge. At $\mathrm{pH}=4-6$, the N-GLPs $750_{6}$ layers contained high positive charge density. Therefore, strong electrostatic attraction existed between N-GLPs $750_{6}$ 
and BPA. Correspondingly, the removal efficiency of BPA showed a high level at $\mathrm{pH}=4-6$. When the positively charged N-GLPs $750_{6}$ interacted with electronegative pollutants, it possessed enhanced electrostatic attraction for removing BPA in aqueous solution. With the $\mathrm{pH}$ further increasing, there were more negatively charged sites on the surface of adsorbents because of the available hydroxyl ions [47]. In this way, electrostatic repulsion between the negatively charged BPA and N-GLPs $750_{6}$ decreased the adsorption capacity. (2) The pKa of BPA (9.5), which also affected removal efficiency [48]. When the $\mathrm{pH}$ was less than the $\mathrm{pKa}, \mathrm{BPA}$ was present in its molecular form, thus containing a lower negative charge. However, when the $\mathrm{pH}$ of the solution was higher than the $\mathrm{pKa}$, BPA was present in the form of the phenolate ion. With the hydroxyl ion increasing, BPA was highly negatively charged. Moreover, the number of negatively charged sites on the N-GLPs $750_{6}$ also rose. The electrostatic repulsion between BPA and N-GLPs $750_{6}$ induced the decrease in adsorption capacity and removal efficiency. The equilibrium $\mathrm{pH}$ for BPA adsorption was also measured. As shown in Figure 10, when the equilibrium $\mathrm{pH}$ was lower, the removal efficiency of BPA increased. In contrast, when the equilibrium $\mathrm{pH}$ was higher, the adsorption of BPA was negatively influenced, which corresponds to the conclusions from the analysis of the initial $\mathrm{pH}$. Combining the removal efficiency and the feasibility in practical application, we chose $\mathrm{pH}$ of 6 as the optimal adsorption condition.

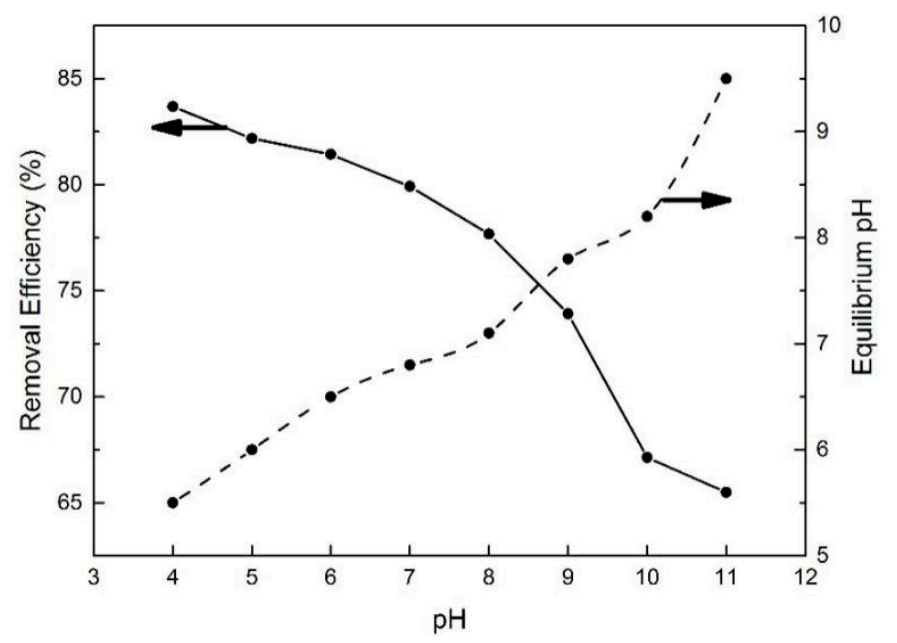

Figure 10. Effect of $\mathrm{pH}$ on removal efficiency and equilibrium $\mathrm{pH}$ (experimental conditions: initial concentration $=10 \mathrm{mg} / \mathrm{L}$, adsorbent dose $=7.0 \mathrm{~g} / \mathrm{L}$, contact time $=48 \mathrm{~h}, \mathrm{~T}=30^{\circ} \mathrm{C}$ ).

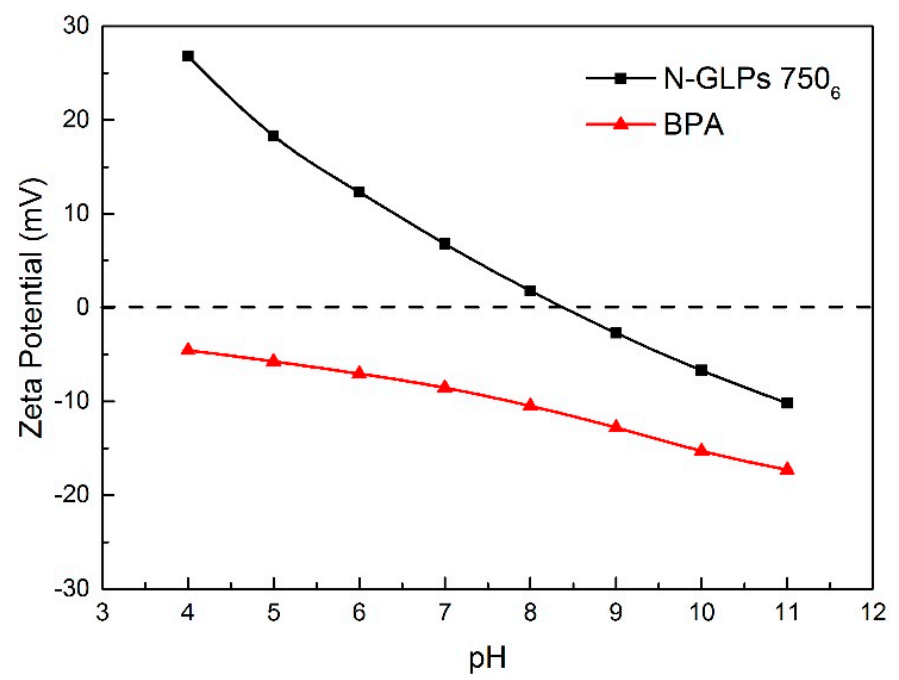

Figure 11. Zeta potentials of adsorbent and pollutant in $0.001 \mathrm{M} \mathrm{NaCl}$ solution $\left(25^{\circ} \mathrm{C}\right)$. 


\subsubsection{Effect of Temperature}

Temperature exerts a major effect on the adsorption capacity of BPA. The effect of temperature on the adsorption of BPA with N-GLPs $750_{6}$ was investigated in a temperature range from 10 to $60{ }^{\circ} \mathrm{C}$ at constant $\mathrm{pH}(6.0)$ and contact time (48 h). As shown in Figure 12, the removal efficiency of BPA on N-GLPs $750_{6}$ rose with increasing temperature, indicating that the adsorption of BPA onto N-GLPs $750_{6}$ was endothermic. In addition, Brownian movement of BPA molecules increased with rising temperature, which resulted in an increase in the rate of mass transfer from the liquid phase to the solid/liquid phase [49]. BPA would have been attached on the surface of N-GLPs $750_{6}$ and led to further interaction when they became closer. The viscosity of bulk also decreased with increasing temperature, thus augmenting the mobility of BPA in aqueous solution. Moreover, the active sites on N-GLPs $750_{6}$ contained intensive electrostatic attraction with BPA at higher temperatures [47]. Overall, the increase in temperature enhanced the interaction between BPA and N-GLPs $750_{6}$ and modified the adsorption condition. Considering removal efficiency and economic feasibility, we chose $50{ }^{\circ} \mathrm{C}$ as the ideal adsorption temperature.

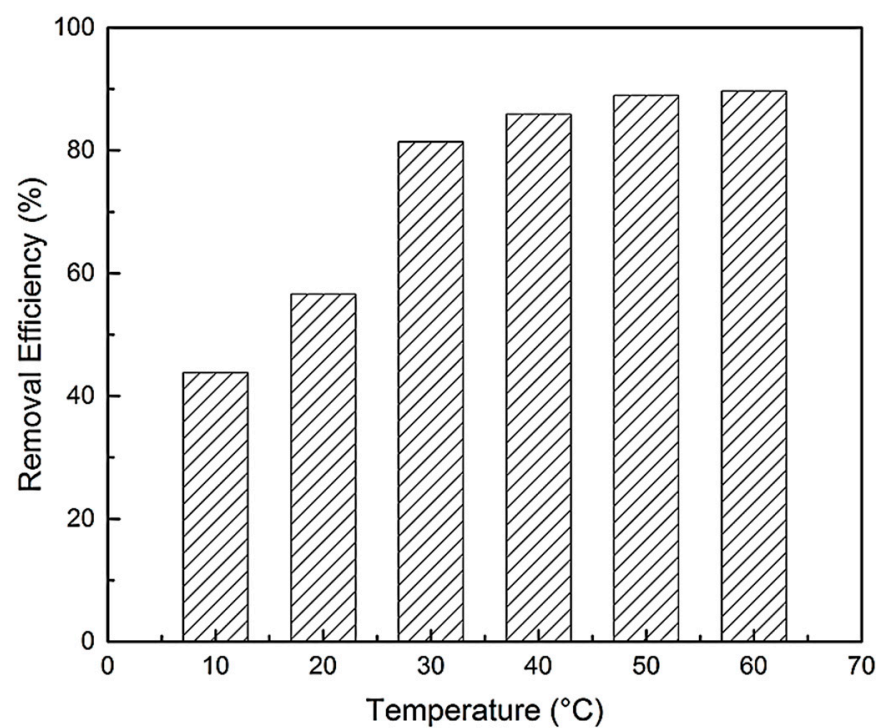

Figure 12. Effect of temperature on removal efficiency (experimental conditions: adsorbent dose $=7.0 \mathrm{~g} / \mathrm{L}$, initial concentration $=10 \mathrm{mg} / \mathrm{L}$, contact time $=48 \mathrm{~h}, \mathrm{pH}=6.0)$.

\subsubsection{BPA Adsorption Isotherms and Thermodynamics Studies}

It is important to identify and understand the adsorption mechanisms and the interactions between BPA and the adsorbents through equilibrium adsorption isotherms [50]. The adsorption isotherms of BPA on N-GLPs $750_{6}$ at different temperatures are shown in Figure S1. The Langmuir and Freundlich isotherms were utilized to analyze the equilibrium adsorption data. The equations are expressed as follows [42,51-53]:

$$
\begin{gathered}
\text { Langmuir isotherm : } q_{e}=\frac{q_{\max } K_{L} c_{e}}{\left(1+K_{L} c_{e}\right)} \\
\text { Freundlich isotherm : } q_{e}=K_{F} c_{e}^{1 / n}
\end{gathered}
$$

where $q_{e}$ is the equilibrium adsorption concentration of BPA $(\mathrm{mg} / \mathrm{g}) ; c_{e}$ is the equilibrium BPA concentration in aqueous solution $(\mathrm{mg} / \mathrm{L}) ; q_{\max }$ is the maximum adsorption capacity $(\mathrm{mg} / \mathrm{g}) ; K_{L}$ is the Langmuir isotherm constant $(\mathrm{L} / \mathrm{mg})$; and $K_{F}$ and $n$ are the Freundlich isotherm constant and adsorption capacity parameter, respectively.

Table S2 shows the values of $K_{L}, q_{m}, K_{F}$, and $n$ and the correlation coefficients for Langmuir and Freundlich. Compared with the Freundlich model (0.9580-0.9376), the Langmuir model (0.9982-0.9922) contained much better correlation coefficients, indicating that the adsorption of BPA on N-GLPs $750_{6}$ 
was inclined to monolayer adsorption on homogeneous adsorbent surfaces. Furthermore, with rising temperature, the increase in $q_{m}$ demonstrated that adsorption was facilitated.

The thermodynamic parameters were next evaluated by the following equations to confirm the conditions of the adsorption process [52,53]:

$$
\begin{gathered}
K_{C}=\frac{q_{e}}{c_{e}} \\
\Delta G^{\circ}=-R T \ln K_{C} \\
\Delta G^{\circ}=\Delta H^{\circ}-T \Delta S^{\circ} \\
\ln K_{C}=-\frac{\Delta H^{\circ}}{R T}+\frac{\Delta S^{\circ}}{R}
\end{gathered}
$$

where $K_{C}$ is the adsorption equilibrium constant, calculated by $q_{e}$ and $c_{e}$ at initial concentration $=$ $10 \mathrm{mg} / \mathrm{L} ; R$ is the gas constant $\left(8.314 \mathrm{~J} \cdot \mathrm{mol}^{-1} \mathrm{~K}^{-1}\right)$; and $T$ is the temperature in Kelvin.

As shown in Table $\mathrm{S} 3$, the negative values of $\Delta G^{\circ}(-0.97$ to $-7.13 \mathrm{KJ} / \mathrm{mol})$ suggested a spontaneous adsorption process, and the decrease in values with increasing temperature indicated that adsorption was promoted at high temperatures. The positive value of $\Delta H^{\circ}(42.01 \mathrm{KJ} / \mathrm{mol})$ also suggested that the adsorption process was endothermic, which led to the increase in adsorption capacity at higher temperatures. Moreover, the positive value of $\Delta S^{\circ}\left(150.41 \mathrm{~J} \cdot \mathrm{mol}^{-1} \cdot \mathrm{K}^{-1}\right)$ showed an increase in the number of species and randomness at the N-GLPs $750_{6} /$ water interface [54].

\subsubsection{Adsorption Mechanism}

The adsorption mechanism of BPA onto N-GLPs $750_{6}$ was further clarified with the structural analyses of N-GLPs $750_{6}$ and adsorption experiment. As shown in Figure 13, with the structural features of nitrogen-doped graphene-like plates and the adsorption isotherms, the following three main interactions could be related to the adsorption of BPA on N-GLPs 7506: (1) The strong electrostatic interaction between BPA and the N-GLPs $750_{6}$. Electrostatic attraction significantly promoted the adsorption process [55]. When interacting with negatively charged BPA in aqueous solution, the N-GLPs $750_{6}$ with positive charge possessed enhanced electrostatic attraction for removing pollutants, resulting in higher removal efficiency. (2) The hydrogen bonding between the oxygen-containing groups contained in both BPA and N-GLPs $750_{6}$. With the FT-IR result (Figure 7d), some oxygen-containing groups, such as hydroxyl groups, remained in N-GLPs 7506. In aqueous solution, the hydroxyl groups of BPA and adsorbent will form hydrogen bonds to increase the adsorption ability. (3) The $\pi-\pi$ interaction that might exist between the N-GLPs $750_{6}$ planes and the benzene rings of BPA. N-GLPs $750_{6}$ possessed structural units that were similar to benzene rings through calcination and nitrogen doping. Therefore, $\pi-\pi$ electron coupling might exist between the $\pi$ electrons of benzene rings on BPA and N-GLPs $750_{6}$, thus forming a $\pi-\pi$ interaction [56]. With all of these strong interactions, N-GLPs $750_{6}$ obtained a great adsorption capacity of BPA.

\subsubsection{Desorption and Regeneration of N-GLPs $750_{6}$}

In practical applications of pollutant removal, high adsorption capacity and good recyclability are requisite [57]. In this way, it is important to test the regeneration performance of N-GLPs $750_{6}$ in order to evaluate the economic feasibility in practical BPA removal applications. The regeneration of N-GLPs $750_{6}$ was determined using a simple solvent (ethyl/water: 4/1, v/v) washing method under ultrasound (US) irradiation [5]. The separation of N-GLPs $750_{6}$ and liquid phase was carried out by centrifuging at $9000 \mathrm{rpm}$ for $15 \mathrm{~min}$ and then stoved in an oven at $80^{\circ} \mathrm{C}$ for $30 \mathrm{~min}$. The resulting N-GLPs $750_{6}$ sample was used again for the next recycling experiment. Adsorption-desorption experiments were repeated for six cycles in this study. Figure 14 shows that the removal efficiencies of BPA were decreased after each adsorption cycle. This phenomenon might have resulted from the occupation of the adsorption sites at the surface of N-GLPs $750_{6}$. After six adsorption-desorption cycles, the removal efficiency of 
BPA decreased from $92.0 \%$ to $80.4 \%$, which is still an appropriate efficiency for industrial application. Therefore, according to the regeneration study, it was concluded that N-GLPs $750_{6}$ possess great regeneration ability and can be used in practical application for the treatment of BPA in wastewater.
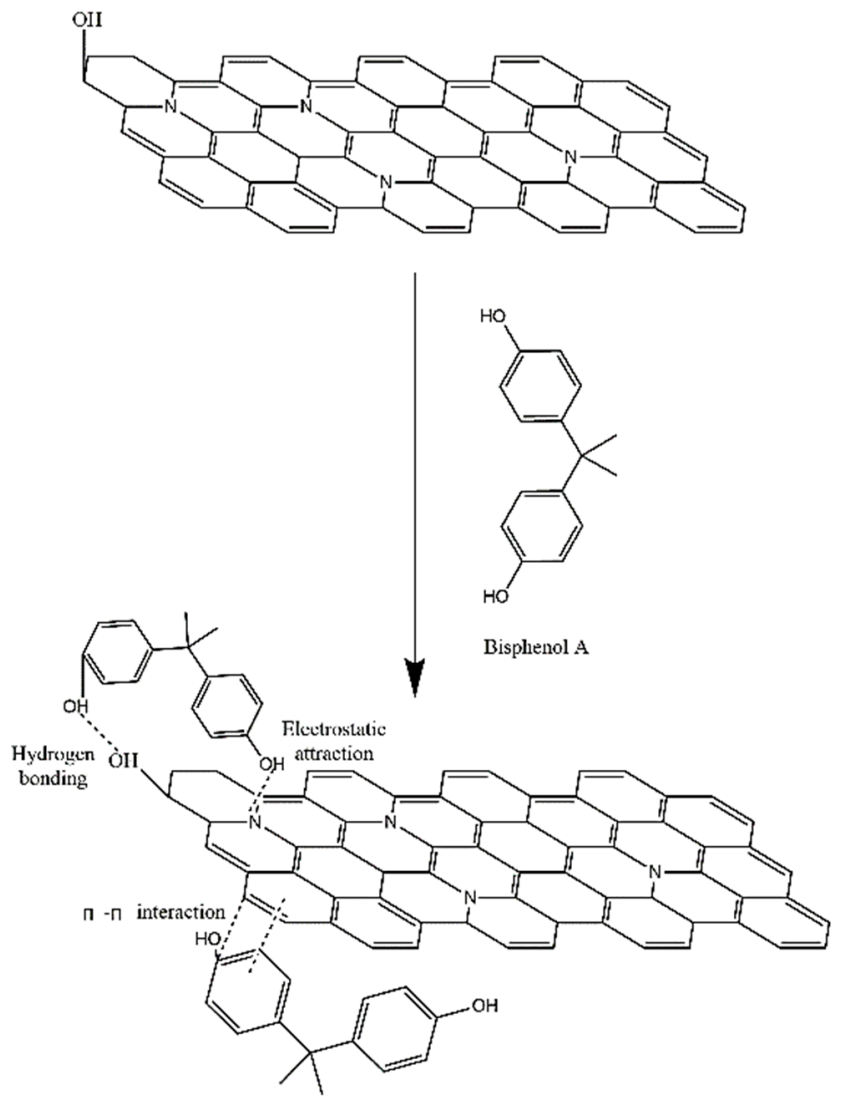

Figure 13. Schematic of adsorption interaction of bisphenol A (BPA) onto N-GLPs $750_{6}$.

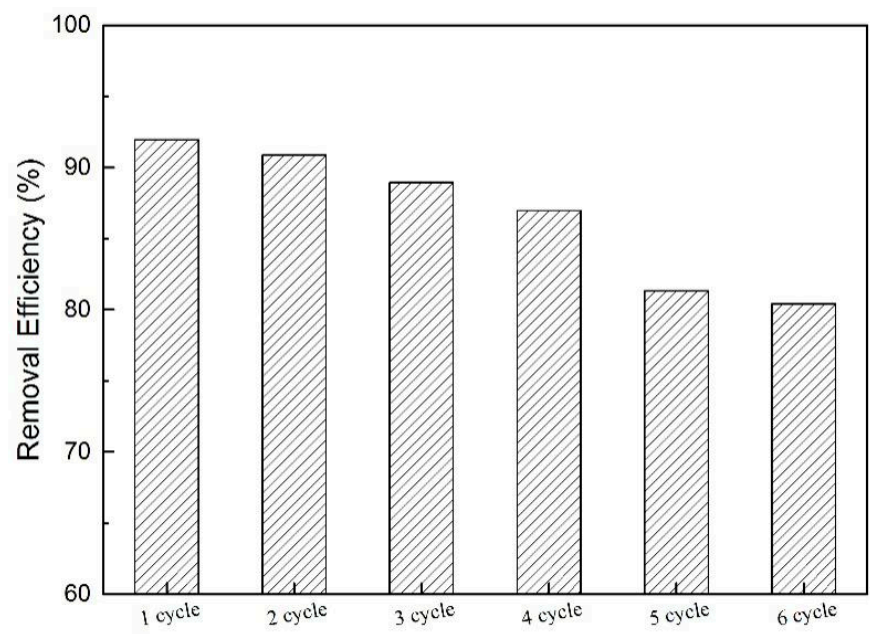

Figure 14. Recyclability of N-GLPs $750_{6}$ for six cycles.

A comparison was made of other carbonaceous adsorbents previously reported in the literature (Table 3) [58-61]. Although the removal efficiency of N-GLPs $750_{6}$ is narrowly lower than that of activated carbon, the preparation of N-GLPs $750_{6}$ is easier and more cost-effective because its raw material is green petroleum coke-a kind of potential pollutant and by-product. Besides, N-GLPs 750 6 also contains great recyclability, which can further reduce the cost. The contact time for N-GLPs $750_{6}$ is also smaller than that of activated carbon. Considering the zeta potential of the adsorbents, the high 
affinity of N-GLPs $750_{6}$ to BPA is even more obvious. Therefore, N-GLPs $750_{6}$ is an excellent BPA absorbent in wastewater treatment.

Table 3. Adsorption capacity of BPA by N-GLPs $750_{6}$ in comparison to other literature values.

\begin{tabular}{ccccccc}
\hline Adsorbent & Pollutant & $\mathbf{p H}$ & $\begin{array}{c}\text { Contact } \\
\text { Time (h) }\end{array}$ & $\begin{array}{c}\mathbf{C}_{\mathbf{0}} \\
(\mathbf{m g} / \mathbf{L})\end{array}$ & $\begin{array}{c}\text { Removal } \\
\text { Efficiency (\%) }\end{array}$ & Reference \\
\hline Activated carbon & BPA & - & 60 & 10 & 94.4 & {$[58]$} \\
Porous carbon & BPA & - & 24 & 5 & 90.0 & {$[59]$} \\
CNTs & BPA & 6.0 & 24 & 10 & 71.8 & {$[60]$} \\
Nitrogen-doped graphene & BPA & 6.0 & 12 & 10 & 90.5 & {$[61]$} \\
N-GLPs 750 & BPA & 6.0 & 48 & 10 & 92.0 & This Work \\
N-GLPs 750 & BPA & 6.0 & 48 & 5 & 98.3 & This Work \\
\hline
\end{tabular}

\section{Materials and Methods}

\subsection{Materials}

Green petroleum coke with 93\% carbon content was purchased from Chambroad Holding Group Co., Ltd. (Shandong, China). $\mathrm{H}_{2} \mathrm{SO}_{4}(98 \%)$ and $\mathrm{NaOH}$ with high chemical purity were purchased from Sinopharm Chemical Reagent Co., Ltd. (Shanghai, China). Melamine was purchased from Kemiou Chemical Reagent Co., Ltd. (Tianjin, China). Bisphenol A was purchased from Macklin Biochemical Co., Ltd. (Shanghai, China). Ethanol was purchased from Fuyu Fine Chemical Co., Ltd. (Tianjin, China). The latter three chemicals were all of analytical grade. Deionized water (resistivity of 18.2 $\mathrm{M} \Omega \mathrm{cm}^{-1}$ ) was achieved using an ultrapure water purifier system (Millipore, Billerica, MA, USA). All chemicals and materials were used without further purification.

\subsection{Characterization}

SEM (JSM-6700F, JEOL, Tokyo, Japan) was used to analyze the structural features and surface morphologies of the green petroleum coke, petroleum coke, and nitrogen-doped graphene-like plates. The acceleration voltage of SEM was $3.0 \mathrm{KV}$, and the mode of operation was SE. An energy-dispersive $X$-ray spectroscopy (EDX) instrument was attached to the JSM-6700F to investigate chemical composition. XRD was conducted on a diffractometer (Rigaku D-Max 2200, Tokyo, Japan) to characterize the structural features of samples at a scanning rate of $2^{\circ} / \mathrm{min}$ in $2 \theta$ range of $10-80^{\circ}$. The XRD data was analyzed by MDI Jade 6. FT-IR (Vector 22, Bruker AXS, Co., Ltd., Karlsruhe, Germany) of the samples was performed using $\mathrm{KBr}$ pellets in reflectance mode from 400 to $4000 \mathrm{~cm}^{-1}$ with a resolution of $2 \mathrm{~cm}^{-1}$ to examine the functional groups. A surface area and porosity analyzer (ASAP, 2020 HD88, Micromeritics, Norcross, GA, USA) was conducted to analyze the pore structure of samples. The BET specific surface area was calculated with multipoint adsorption data in relative pressure $\left(\mathrm{P} / \mathrm{P}_{0}\right)$ between 0.05 and 0.1 , and the $V_{p}$ was obtained at $P / P_{0}=0.998$. XPS was performed to determine the elementary characteristics on the X-ray photoelectron spectrometer (Thermo ESCALAB 250XI, Thermo Fisher Scientific, Waltham, MA, USA). The source gun type was Al K alpha, and the pass energy was $100.0 \mathrm{eV}$ for the XPS survey spectra and $30.0 \mathrm{eV}$ for the $\mathrm{C}(1 \mathrm{~s}), \mathrm{O}(1 \mathrm{~s}), \mathrm{N}(1 \mathrm{~s})$ and S (2p) spectra. The XPS data was analyzed by XPS Peak 4.1. The zeta potential of the samples was measured by a ZetaPALS (Zetasizer NanoZS, Malvern, UK). All the figures were drawn by Origin 9.1 and Photoshop 2018.

\subsection{Preparation of Petroleum Coke}

Green petroleum coke was pulverized by a high-speed pulverizer and passed through a 200-mesh screen to prepare green petroleum coke powder within $75 \mu \mathrm{m}$ of granularity. Green petroleum coke powder in a porcelain boat with a lid was then placed into a corundum tube with a flow of nitrogen atmosphere and heated to $200{ }^{\circ} \mathrm{C}$ at a rate of $10{ }^{\circ} \mathrm{C} / \mathrm{min}$ and directly to $800{ }^{\circ} \mathrm{C}$ at a rate of $5^{\circ} \mathrm{C} / \mathrm{min}$ in a tubular furnace [32]. After the temperature was maintained for $6 \mathrm{~h}$, the furnace was slowly cooled to room temperature, and the petroleum coke was directly collected from the porcelain 
boat. Compared to green petroleum coke, obvious changes occurred in petroleum coke in terms of morphology, microstructure, and particle size (Figure S2a,b). EDX quantitative microanalysis indicated the presence of $\mathrm{C}, \mathrm{N}, \mathrm{O}$, and $\mathrm{S}$ in the green petroleum coke (Figure S3a). After calcination, the elemental content of $\mathrm{N}$ and $\mathrm{O}$ decreased slightly in petroleum coke, while $\mathrm{S}$ disappeared in the EDX spectrum of petroleum coke (Figure S3b). Combining the XPS survey spectra and C(1s), O(1s), and S(2p) spectra of green petroleum coke and petroleum coke (Figure $\mathrm{S} 4$ ) as well as the XPS atomic concentration report (Table S4), the $S$ in green petroleum coke was successfully removed.

\subsection{Preparation of Nitrogen-Doped Graphene-Like Plates}

Nitrogen-doped graphene-like plates were synthesized by calcining a mixture of petroleum coke and melamine powder in a tubular furnace. Melamine powder $(2.0 \mathrm{~g})$ was added to $40 \mathrm{~mL}$ ethanol. After $30 \mathrm{~min}$ of stirring at $70 \mathrm{rpm}$ at $60{ }^{\circ} \mathrm{C}$, petroleum coke powder $(2.0 \mathrm{~g})$ was continuously added into the mixture, with stirring maintained for an additional $30 \mathrm{~min}$. The mixture was then stoved in an oven at $80{ }^{\circ} \mathrm{C}$ for $30 \mathrm{~min}$. The obtained grey-color powder mixture was loaded on a porcelain boat and inserted into a quartz tube of a tubular furnace for thermal annealing [32,38,62]. The N-doped graphene-like plate samples were obtained by annealing the mixture at $350-750{ }^{\circ} \mathrm{C}$ for $2-6 \mathrm{~h}$ under $\mathrm{N}_{2}$ flow.

\subsection{Adsorption Experiments}

The adsorption experiment of bisphenol A was carried out with batch techniques. The adsorbent $(7.0 \mathrm{~g} / \mathrm{L})$ was added into BPA solution $(10-100 \mathrm{mg} / \mathrm{L})$ and mixed uniformly by shaking at $150 \mathrm{rpm}$ for $48 \mathrm{~h}$ at different temperatures $\left(10-60^{\circ} \mathrm{C}\right) . \mathrm{NaOH}$ and $\mathrm{HCl}$ were utilized to adjust the $\mathrm{pH}$ to $4-11$. After the adsorption process, the mixture was centrifuged at $9500 \mathrm{rpm}$ for $15 \mathrm{~min}$ to separate the supernatants. The concentration of BPA was measured with a UV/vis spectrometer (TU-1810 PC, Purkinje, Beijing, China) and calculated by absorbance at $276 \mathrm{~nm}$. The removal efficiency (R) for BPA was calculated as follows:

$$
\mathrm{R}=\left(\mathrm{c}_{0}-\mathrm{c}_{\mathrm{t}}\right) / \mathrm{c}_{0} \times 100 \%
$$

where $c_{0}$ and $c_{t}(\mathrm{mg} / \mathrm{L})$ are concentration of pollutants at initial and specific adsorption times, respectively. The removal amount $\left(\mathrm{Q}_{\mathrm{t}}\right)$ of pollutants by samples was calculated as follows:

$$
\mathrm{Q}_{\mathrm{t}}=\left(\mathrm{c}_{0}-\mathrm{c}_{\mathrm{t}}\right) \mathrm{V} / \mathrm{W}
$$

where $\mathrm{V}(\mathrm{L})$ is the volume of the solution, and $\mathrm{W}(\mathrm{g})$ is the mass of the catalysts. The adsorption isotherms were used to analyze the adsorption mechanisms of BPA onto N-doped graphene-like plates. The desorption and regeneration of the N-GLPs were also examined to figure out the recycling ability.

\section{Conclusions}

In summary, N-GLP samples were successfully synthesized via nitrogen doping and thermal annealing, which offered a potential low-cost and efficient adsorbent to treat BPA in aqueous solution. Green petroleum coke was used as a raw material due to advantages such as its abundance as waste in the oil-refining process and inexpensiveness. N-GLPs $750_{6}$ obtained by calcinating melamine and petroleum coke at $750^{\circ} \mathrm{C}$ for $6 \mathrm{~h}$ exhibited a graphene-like structure according to SEM images and XRD analysis. Moreover, FT-IR analysis and XPS analysis of N-GLPs $750_{6}$ confirmed successful nitrogen doping. BET analysis demonstrated that nitrogen doping and calcination could increase the specific surface area and pore volume of the adsorbent in order to augment adsorption capacity. The zeta potentials of adsorbate and adsorbent indicated strong electrostatic attraction between positive N-GLPs $750_{6}$ and negative BPA, which was the main interaction enhancing the adsorption of more BPA onto the surface of N-GLPs $750_{6}$. Batch adsorption experiments revealed that the removal of BPA depended on contact time, initial $\mathrm{pH}$, and temperature. Furthermore, adsorption experiments showed that N-GLPs $750_{6}$ possessed high adsorption capacity for BPA via electrostatic attraction, hydrogen bonding, 
and $\pi-\pi$ interaction. Thermodynamic studies also revealed that the adsorption process was feasible, spontaneous, endothermic, and controlled by a physisorption process. Therefore, it is suggested that $\mathrm{N}-$ GLPs $750_{6}$ is a promising adsorbent to remove BPA in wastewater.

Supplementary Materials: The following are available online. Figure S1: Adsorption isotherms of BPA on N-GLPs 750 6 (experimental conditions: adsorbent dose $=7.0 \mathrm{~g} / \mathrm{L}$, initial concentration $=10-200 \mathrm{mg} / \mathrm{L}$, contact time $=48 \mathrm{~h}, \mathrm{pH}=6.0, \mathrm{~T}=10-50{ }^{\circ} \mathrm{C}$ ); Figure S2: SEM images of (a) green petroleum coke and (b) petroleum coke; Figure S3: EDX analysis of (a) green petroleum coke and (b) petroleum coke; Figure S4: XPS survey (1) and high-resolution C 1 s (2), O 1 s (3), S 2p (4) spectra of (a) green petroleum coke and (b) petroleum coke; Table S1: Pseudo-first-order and pseudo-second-order kinetic parameters for the adsorption of BPA onto N-GLPs $750_{6}$ at $303 \mathrm{~K}$; Table S2: Langmuir and Freundlich adsorption isotherm parameters for the adsorption of BPA onto N-GLPs $750_{6}$; Table S3: Thermodynamic parameters for the adsorption of BPA onto N-GLPs $750_{6}$; Table S4: XPS atomic concentration report of green petroleum coke and petroleum coke.

Author Contributions: Conceptualization, T.W. and Y.L.; experiments, Z.L.; data curation, Q.W. and B.Z.; writing-original draft preparation, Z.L.; writing-review and editing, T.W. and Y.L. All authors have read and agreed to the published version of the manuscript.

Funding: This work was supported by the National Natural Science Foundation of China (Grant Number 21677087). The authors express appreciation to Jake Carpenter from UCLA for linguistic assistance.

Conflicts of Interest: The authors declare no conflict of interest.

\section{References}

1. Wang, W.; Wang, X.; Xing, J.; Gong, Q.; Wang, H.; Wang, J.; Chen, Z.; Ai, Y.; Wang, X. Multi-heteroatom doped graphene-like carbon nanospheres with $3 \mathrm{D}$ inverse opal structure: A promising bisphenol-A remediation material. Environ. Sci. Nano 2019, 6, 809-819. [CrossRef]

2. Mauck, J.R.; Bassett, A.W.; Sadler, J.M.; La Scala, J.J.; Napadensky, E.; Reno, K.H.; Stanzione, J.F. Synthesis and characterization of a lignin-derived aromatic polycarbonate. J. Biobased Mater. Bioenergy 2018, 12, 471-476. [CrossRef]

3. Liu, Y.; Yao, L.; He, L.; Liu, N.; Piao, Y. Electrochemical Enzyme Biosensor Bearing Biochar Nanoparticle as Signal Enhancer for Bisphenol A Detection in Water. Sensors 2019, 19, 1619. [CrossRef]

4. Nie, M.; Deng, Y.; Nie, S.; Yan, C.; Ding, M.; Dong, W.; Dai, Y.; Zhang, Y. Simultaneous removal of bisphenol A and phosphate from water by peroxymonosulfate combined with calcium hydroxide. Chem. Eng. J. 2019, 369, 35-45. [CrossRef]

5. Bhadra, B.N.; Lee, J.K.; Cho, C.-W.; Jhung, S.H. Remarkably efficient adsorbent for the removal of bisphenol A from water: Bio-MOF-1-derived porous carbon. Chem. Eng. J. 2018, 343, 225-234. [CrossRef]

6. Xiao, P.; Wang, P.; Li, H.; Li, Q.; Shi, Y.; Wu, X.-L.; Lin, H.; Chen, J.; Wang, X. New insights into bisphenols removal by nitrogen-rich nanocarbons: Synergistic effect between adsorption and oxidative degradation. J. Hazard. Mater. 2018, 345, 123-130. [CrossRef]

7. Yuan, M.; Tong, S.; Zhao, S.; Jia, C.Q. Adsorption of polycyclic aromatic hydrocarbons from water using petroleum coke-derived porous carbon. J. Hazard. Mater. 2010, 181, 1115-1120. [CrossRef]

8. Tripathi, N.; Singh, R.S.; Hills, C.D. Microbial removal of sulphur from petroleum coke (petcoke). Fuel 2019, 235, 1501-1505. [CrossRef]

9. Caruso, J.A.; Zhang, K.; Schroeck, N.J.; McCoy, B.; McElmurry, S.P. Petroleum Coke in the Urban Environment: A Review of Potential Health Effects. Int. J. Environ. Res. Public Health 2015, 12, 6218-6231. [CrossRef] [PubMed]

10. Wu, M.; Wang, Y.; Wu, W.; Hu, C.; Wang, X.; Zheng, J.; Li, Z.; Jiang, B.; Qiu, J. Preparation of functionalized water-soluble photoluminescent carbon quantum dots from petroleum coke. Carbon 2014, 78, 480-489. [CrossRef]

11. Li, P.; Hwang, J.-Y.; Park, S.-M.; Sun, Y.-K. Superior lithium/potassium storage capability of nitrogen-rich porous carbon nanosheets derived from petroleum coke. J. Mater. Chem. A 2018, 6, 12551-12558. [CrossRef]

12. Andrews, A.; Lattanzio, R.K. Petroleum Coke: Industry and Environmental Issues; Congressional Research Service: Washington, DC, USA, 2014; pp. 91-99.

13. Jeong, D.S.; Yun, J.M.; Kim, K.H. Nitrogen-doped carbon from waste cardboard recycling for electric double-layer capacitors. Nanosci. Nanotech. Let. 2018, 10, 809-813. [CrossRef] 
14. Sethia, G.; Sayari, A. Nitrogen-doped carbons: Remarkably stable materials for $\mathrm{CO}_{2}$ capture. Energy Fuels 2014, 28, 2727-2731. [CrossRef]

15. Javed, H.; Luong, D.X.; Lee, C.G.; Zhang, D.; Tour, J.M.; Alvarez, P.J.J. Efficient removal of bisphenol-A by ultra-high surface area porous activated carbon derived from asphalt. Carbon N. Y. 2018, 140, 441-448. [CrossRef]

16. Li, C.; Liu, X.; Zhou, Z.; Dai, Z.; Yang, J.; Wang, F. Effect of heat treatment on structure and gasification reactivity of petroleum coke. Int. J. Coal Sci. Technol. 2016, 3, 53-61. [CrossRef]

17. Eren, E.; Cubuk, O.; Ciftci, H.; Eren, B.; Caglar, B. Adsorption of basic dye from aqueous solutions by modified sepiolite: Equilibrium, kinetics and thermodynamics study. Desalination 2010, 252, 88-96. [CrossRef]

18. Zhang, B.; Dong, Z.; Sun, D.; Wu, T.; Li, Y. Enhanced adsorption capacity of dyes by surfactant-modified layered double hydroxides from aqueous solution. J. Ind. Eng. Chem. 2017, 49, 208-218. [CrossRef]

19. Wang, M.; Zhang, B.; Li, G.; Wu, T.; Sun, D. Efficient remediation of crude oil-contaminated soil using a solvent/surfactant system. Rsc Adv. 2019, 9, 2402-2411. [CrossRef]

20. Hoffmann, J.; Jensen, C.U.; Rosendahl, L.A. Co-processing potential of HTL bio-crude at petroleum refineries-Part 1: Fractional distillation and characterization. Fuel 2016, 165, 526-535. [CrossRef]

21. Colati, K.A.P.; Dalmaschio, G.P.; de Castro, E.V.R.; Gomes, A.O.; Vaz, B.G.; Romão, W. Monitoring the liquid/liquid extraction of naphthenic acids in brazilian crude oil using electrospray ionization FT-ICR mass spectrometry (ESI FT-ICR MS). Fuel 2013, 108, 647-655. [CrossRef]

22. Yu, J.; Guo, M.; Muhammad, F.; Wang, A.; Zhang, F.; Li, Q.; Zhu, G. One-pot synthesis of highly ordered nitrogen-containing mesoporous carbon with resorcinol-urea-formaldehyde resin for $\mathrm{CO}_{2}$ capture. Carbon 2014, 69, 502-514. [CrossRef]

23. Bai, R.; Yang, M.; Hu, G.; Xu, L.; Hu, X.; Li, Z.; Wang, S.; Dai, W.; Fan, M. A new nanoporous nitrogen-doped highly-efficient carbonaceous $\mathrm{CO}_{2}$ sorbent synthesized with inexpensive urea and petroleum coke. Carbon 2015, 81, 465-473. [CrossRef]

24. Shen, W.; Zhang, S.; He, Y.; Li, J.; Fan, W. Hierarchical porous polyacrylonitrile-based activated carbon fibers for $\mathrm{CO}_{2}$ capture. J. Mater. Chem. 2011, 21, 14036-14040. [CrossRef]

25. Yang, M.; Guo, L.; Hu, G.; Hu, X.; Chen, J.; Shen, S.; Dai, W.; Fan, M. Adsorption of $\mathrm{CO}_{2}$ by Petroleum Coke Nitrogen-Doped Porous Carbons Synthesized by Combining Ammoxidation with $\mathrm{KOH}$ Activation. Ind. Eng. Chem. Res. 2016, 55, 757-765. [CrossRef]

26. Liu, L.; Deng, Q.-F.; Ma, T.-Y.; Lin, X.-Z.; Hou, X.-X.; Liu, Y.-P.; Yuan, Z.-Y. Ordered mesoporous carbons: Citric acid-catalyzed synthesis, nitrogen doping and $\mathrm{CO}_{2}$ capture. J. Mater. Chem. 2011, 21, 16001-16009. [CrossRef]

27. Zhang, Y.; Zhang, Y.; Huang, J.; Du, D.; Xing, W.; Yan, Z. Enhanced capacitive performance of N-doped activated carbon from petroleum coke by combining ammoxidation with $\mathrm{KOH}$ activation. Nanoscale Res. Lett. 2016, 11, 245. [CrossRef]

28. Sarkar, B.; Xi, Y.; Megharaj, M.; Naidu, R. Orange II adsorption on palygorskites modified with alkyl trimethylammonium and dialkyl dimethylammonium bromide-An isothermal and kinetic study. Appl. Clay Sci. 2011, 51, 370-374. [CrossRef]

29. Long, D.; Li, W.; Ling, L.; Miyawaki, J.; Mochida, I.; Yoon, S.-H. Preparation of Nitrogen-Doped Graphene Sheets by a Combined Chemical and Hydrothermal Reduction of Graphene Oxide. Langmuir 2010, 26, 16096-16102. [CrossRef]

30. Chen, X.; Ching, W.K.; Lam, K.F.; Wei, W.; Yeung, K.L. An Investigation of the Selective Adsorptions of Metals on Mesoporous $\mathrm{NH}_{2}-\mathrm{MCM}-41$. J. Phys. Chem. C 2016, 120, 18365-18376. [CrossRef]

31. Deng, B.; Wang, D.; Jiang, Z.; Zhang, J.; Shi, S.; Jiang, Z.-J.; Liu, M. Amine group induced high activity of highly torn amine functionalized nitrogen-doped graphene as the metal-free catalyst for hydrogen evolution reaction. Carbon 2018, 138, 169-178. [CrossRef]

32. Sheng, Z.H.; Shao, L.; Chen, J.J.; Bao, W.J.; Wang, F.B.; Xia, X.H. Catalyst-Free synthesis of nitrogen-doped graphene via thermal annealing graphite oxide with melamine and its excellent electrocatalysis. Acs Nano 2011, 5, 4350-4358. [CrossRef] [PubMed]

33. Miao, F.J.; Miao, R.; Yu, Z.; Shi, C.P.; Zhu, L.; Chu, P.K. A stacked structure comprising 3-dimensional nitrogen-doped graphene, silicon microchannel plate, and $\mathrm{TiO}_{2}$ for high-performance anode in lithium-ion battery. Mater. Express 2019, 9, 629-634. [CrossRef] 
34. Xiao, P.Y.; Wang, K.B.; Chen, Z.; Zhou, N.; Wang, T.H.; Zhang, M. The improvement of $\mathrm{SiO}_{2}$ nanoparticles on the oxygen reduction reaction property of nitrogen-doped mesoporous graphene spheres prepared by spray drying. Nanosci. Nanotech. Let. 2018, 10, 200-206. [CrossRef]

35. Zhang, E.L.; Sun, T.; Ge, B.T.; Zhang, W.G.; Gao, X.; Jiang, H.; Li, Z.C.; Liu, G.J.; Shen, J. High-performance solar-blind photodetector with graphene and nitrogen-doped reduced graphene oxide quantum dots (rGOQDs). Mater. Express 2018, 8, 105-111. [CrossRef]

36. Sun, H.; Wang, Y.; Liu, S.; Ge, L.; Wang, L.; Zhu, Z.; Wang, S. Facile synthesis of nitrogen doped reduced graphene oxide as a superior metal-free catalyst for oxidation. Chem. Commun. 2013, 49, 9914-9916. [CrossRef] [PubMed]

37. Zhu, M.; Muhammad, Y.; Hu, P.; Wang, B.; Wu, Y.; Sun, X.; Tong, Z.; Zhao, Z. Enhanced interfacial contact of dopamine bridged melamine-graphene/ $\mathrm{TiO}_{2}$ nano-capsules for efficient photocatalytic degradation of gaseous formaldehyde. Appl. Catal. B Environ. 2018, 232, 182-193. [CrossRef]

38. Soo, L.T.; Loh, K.S.; Mohamad, A.B.; Daud, W.R.W.; Wong, W.Y. Effect of nitrogen precursors on the electrochemical performance of nitrogen-doped reduced graphene oxide towards oxygen reduction reaction. J. Alloys Compd. 2016, 677, 112-120. [CrossRef]

39. Wang, Z.; Li, P.; Chen, Y.; Liu, J.; Tian, H.; Zhou, J.; Zhang, W.; Li, Y. Synthesis of nitrogen-doped graphene by chemical vapour deposition using melamine as the sole solid source of carbon and nitrogen. J. Mater. Chem. C 2014, 2, 7396-7401. [CrossRef]

40. Dehghani, M.H.; Mahvi, A.H.; Rastkari, N.; Saeedi, R.; Nazmara, S.; Iravani, E. Adsorption of bisphenol A (BPA) from aqueous solutions by carbon nanotubes: Kinetic and equilibrium studies. Desalin. Water Treat. 2015, 54, 84-92. [CrossRef]

41. Guo, W.; Hu, W.; Pan, J.; Zhou, H.; Guan, W.; Wang, X.; Dai, J.; Xu, L. Selective adsorption and separation of BPA from aqueous solution using novel molecularly imprinted polymers based on kaolinite/ $\mathrm{Fe}_{3} \mathrm{O}_{4}$ composites. Chem. Eng. J. 2011, 171, 603-611. [CrossRef]

42. Kabiri, S.; Tran, D.N.H.; Azari, S.; Losic, D. Graphene-Diatom Silica Aerogels for Efficient Removal of Mercury Ions from Water. Acs Appl. Mater. Interfaces 2015, 7, 11815-11823. [CrossRef]

43. Travlou, N.A.; Kyzas, G.Z.; Lazaridis, N.K.; Deliyanni, E.A. Graphite oxide/chitosan composite for reactive dye removal. Chem. Eng. J. 2013, 217, 256-265. [CrossRef]

44. Tan, P.; Bi, Q.; Hu, Y.; Fang, Z.; Chen, Y.; Cheng, J. Effect of the degree of oxidation and defects of graphene oxide on adsorption of $\mathrm{Cu}^{2+}$ from aqueous solution. Appl. Surf. Sci. 2017, 423, 1141-1151. [CrossRef]

45. Travlou, N.A.; Kyzas, G.Z.; Lazaridis, N.K.; Deliyanni, E.A. Functionalization of Graphite Oxide with Magnetic Chitosan for the Preparation of a Nanocomposite Dye Adsorbent. Langmuir 2015, 29, 1657-1668. [CrossRef] [PubMed]

46. Ramesha, G.K.; Vijaya Kumara, A.; Muralidhara, H.B.; Sampath, S. Graphene and graphene oxide as effective adsorbents toward anionic and cationic dyes. J. Colloid Interface Sci. 2011, 361, 270-277. [CrossRef]

47. Machedi, S.; Ejidike, I.P.; Mtunzi, F.M.; Pakade, V.E.; Klink, M.J. Chlorinated Phenols Sorption Performance by Macadamia Activated Carbon and Grafted Macadamia Activated Carbon: Characterization, Kinetics, and Thermodynamic studies. Orient. J. Chem. 2019, 35, 1469-1479. [CrossRef]

48. Qi, C.; Liu, X.; Lin, C.; Zhang, H.; Li, X.; Ma, J. Activation of peroxymonosulfate by microwave irradiation for degradation of organic contaminants. Chem. Eng. J. 2017, 315, 201-209. [CrossRef]

49. Ibrahim, S.; Wang, S.; Ang, H.M. Removal of emulsified oil from oily wastewater using agricultural waste barley straw. Biochem. Eng. J. 2010, 49, 78-83. [CrossRef]

50. Farah, J.Y.; El-Gendy, N.S.; Farahat, L.A. Biosorption of Astrazone Blue basic dye from an aqueous solution using dried biomass of Baker's yeast. J. Hazard. Mater. 2007, 148, 402-408. [CrossRef]

51. Sidik, S.M.; Jalil, A.A.; Triwahyono, S.; Adam, S.H.; Satar, M.A.H.; Hameed, B.H. Modified oil palm leaves adsorbent with enhanced hydrophobicity for crude oil removal. Chem. Eng. J. 2012, 203, 9-18. [CrossRef]

52. Wang, D.; Liu, L.; Jiang, X.; Yu, J.; Chen, X.; Chen, X. Adsorbent for p-phenylenediamine adsorption and removal based on graphene oxide functionalized with magnetic cyclodextrin. Appl. Surf. Sci. 2015, 329, 197-205. [CrossRef]

53. Zhao, D.; Gao, X.; Wu, C.; Xie, R.; Feng, S.; Chen, C. Facile preparation of amino functionalized graphene oxide decorated with $\mathrm{Fe}_{3} \mathrm{O}_{4}$ nanoparticles for the adsorption of $\mathrm{Cr}$ (VI). Appl. Surf. Sci. 2016, 384, 1-9. [CrossRef] 
54. Li, Y.; Wang, M.; Sun, D.; Li, Y.; Wu, T. Effective removal of emulsified oil from oily wastewater using surfactant-modified sepiolite. Appl. Clay Sci. 2018, 157, 227-236. [CrossRef]

55. Hu, Y.; Guo, T.; Ye, X.; Li, Q.; Guo, M.; Liu, H.; Wu, Z. Dye adsorption by resins: Effect of ionic strength on hydrophobic and electrostatic interactions. Chem. Eng. J. 2013, 228, 392-397. [CrossRef]

56. Wu, T.; Cai, X.; Tan, S.; Li, H.; Liu, J.; Yang, W. Adsorption characteristics of acrylonitrile, p-toluenesulfonic acid, 1-naphthalenesulfonic acid and methyl blue on graphene in aqueous solutions. Chem. Eng. J. 2011, 173, 144-149. [CrossRef]

57. Xi, P.; Huang, L.; Xu, Z.; Chen, F.; An, L.; Wang, B.; Chen, Z.N. Low cost and robust soot dipped polyurethane sponge for highly efficient and recyclable oil and organic solvent cleanup. Rsc Adv. 2014, 4, 59481-59485. [CrossRef]

58. Asada, T.; Oikawa, K.; Kawata, K.; Ishihara, S.; Iyobe, T.; Yamada, A. Study of Removal Effect of Bisphenol A and. BETA-Estradiol by Porous Carbon. J. Health Sci. 2004, 50, 588-593. [CrossRef]

59. Koduru, J.R.; Lingamdinne, L.P.; Singh, J.; Choo, K.H. Effective removal of bisphenol-A (BPA) from water using a goethite/activated carbon composite. Process. Saf. Environ. Prot. 2016, 103, 87-96. [CrossRef]

60. Kuo, C.Y. Comparison with as-grown and microwave modified carbon nanotubes to removal aqueous bisphenol A. Desalination 2009, 249, 976-982. [CrossRef]

61. Zhang, B.; Wu, T.; Sun, D.; Chen, W.; Li, G.; Li, Y. NH $\mathrm{NH}_{2}-\mathrm{MCM}-41$ supported on nitrogen-doped graphene as bifunctional composites for removing phenol compounds: Synergistic effect between catalytic degradation and adsorption. Carbon N. Y. 2019, 147, 312-322. [CrossRef]

62. Liu, Y.; Feng, Q.; Tang, N.; Wan, X.; Liu, F.; Lv, L.; Du, Y. Increased magnetization of reduced graphene oxide by nitrogen-doping. Carbon 2013, 60, 549-551. [CrossRef]

Sample Availability: Samples of the compounds are not available from the authors.

(C) 2020 by the authors. Licensee MDPI, Basel, Switzerland. This article is an open access article distributed under the terms and conditions of the Creative Commons Attribution (CC BY) license (http://creativecommons.org/licenses/by/4.0/). 